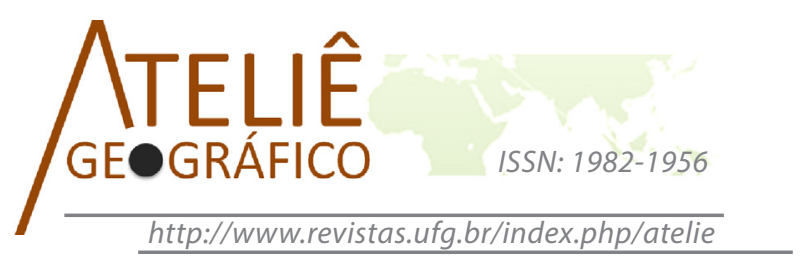

\title{
A formação da Estrada de Ferro Goiás e a urbanização no Sudeste Goiano na primeira metade do século $X X$
}

\author{
The formation of the Estrada de Ferro Goiás and the \\ urbanization in the Goiano Southeast in the first half of the \\ 20th century
}

\section{La formación del Ferrocarril Goiás y la urbanización en el Sudeste de Goiás en la primera mitad del siglo XX}

\author{
Rômulo Hemilton Rocha Marinho \\ Universidade Federal de Goiás \\ romulo135@gmail.com
}

Dallys Dantas

Secretaria Municipal de Educação de Aparecida de Goiânia

dallysdantas@gmail.com

\begin{abstract}
Resumo
As revoluções burguesas ocorridas na Europa a partir do século XVIII promoveram, em várias partes do globo, condições para o desenvolvimento de uma economia vinculada às ferrovias. Considerando que esse processo implicou a implantação de uma rede ferroviária no território goiano, o objetivo deste trabalho é analisar a formação da Estrada de Ferro Goiás e sua influência na urbanização e no cotidiano dos municípios servidos pelos trilhos. Os procedimentos metodológicos basearam-se em pesquisa bibliográfica, análise documental, levantamento de dados secundários, realização de trabalhos de campo e mapeamento da localização dos trilhos. A análise centrou nas interpretações de fatos locais e na contextualização da ferrovia enquanto fator importante no processo de produção do território e de modernização territorial. Constatou-se que a formação da Estrada de Ferro não só alterou a configuração econômica do território goiano, como também influenciou o seu processo de urbanização, provocando significativas transformações no cotidiano da sociedade goiana à época.
\end{abstract}

Palavras-chave: Estrada de Ferro Goiás; Urbanização; Cotidiano. 


\begin{abstract}
The bourgeois revolutions that took place in Europe from the eighteenth century onwards promoted, in various parts of the globe, conditions for the development of an economy linked to railroads. Considering that this process caused the implantation of a railroad network in the territory of Goiás, the objective of this paper is to analyze the formation of the Estrada de Ferro Goiás and its influence on urbanization and on the daily lives of cities that benefited from the rails. The methodological procedures were based on bibliographic research, documentary analysis, secondary data collection, fieldwork and the mapping of the rails location. The analysis was centered in the interpretations of local facts and in the contextualization of the railroad as a crucial factor in the production process of the territory and the territorial modernization. It was found that not only did the railroad alter the economic configuration of the goiano territory, but it also influenced its urbanization process, causing significant transformations to daily lives of the goiana society at the time.
\end{abstract}

Keywords: Estrada de Ferro Goiás ; Urbanization; Daily Life.

\begin{abstract}
Resumen
Las revoluciones burguesas ocurridas en Europa a partir del siglo XVIII promovieron, en varias partes del mundo, condiciones para el desarrollo de una economía vinculada a los ferrocarriles. Considerando que este proceso implicó la implantación de una red ferroviaria en el territorio goiano, el objetivo de este trabajo es analizar la formación del Ferrocarril en Goiás y su influencia en la urbanización y en el cotidiano de los municipios servidos por los carriles. Los procedimientos metodológicos se basaron en investigación bibliográfica, análisis documental, relevamiento de datos, realización de trabajos de campo y el mapeo de la ubicación de los rieles. El análisis se centró en las interpretaciones de hechos locales y en la contextualización del ferrocarril que es un factor importante en el proceso de producción del territorio y de modernización territorial. Se constató que la formación de la carretera de hierro no sólo alteró la configuración económica del territorio goiano, como también influenció su proceso de urbanización, provocando significativas transformaciones en el cotidiano de la sociedad en la época.
\end{abstract}

Palabras clave: Ferrocarril Goiás; urbanización; Cotidiano.

\title{
Introdução
}

A história da Estrada de Ferro Goiás (EFG) entrelaça-se à história de muitos municípios do Sudeste Goiano e também à de algumas famílias dessa região. Quando, em 1913, os trilhos vindos do sudeste brasileiro alcançam Goiás, inaugura-se novas possibilidades de integração do território goiano ao mercado nacional e sua abertura ao advento da modernização territorial. A implantação da rede ferroviária viabilizou maior comunicação e interação com o centro econômico do país (Sudeste), alterando, portanto, o paradigma da distância. Tamanha a influência da Estrada de Ferro na consolidação da porção sudeste do território goiano, que, entre outros aspectos, a região de planejamento é oficialmente denominada "Sudeste Goiano (Estrada de Ferro)" (IMB, 2006).

Considerando a importância da rede ferroviária no território goiano, o objetivo deste texto é analisar a formação da Estrada de Ferro Goiás e sua influência 
no processo de urbanização e no cotidiano dos núcleos urbanos servidos pelos trilhos. Os procedimentos metodológicos basearam-se no levantamento e análise bibliográfica e documental sobre redes de transportes, urbanização, cotidiano, a EFG, fotografias históricas e aspectos históricos dos municípios do Sudeste Goiano. Também foram realizados trabalhos de campo na região da $\mathrm{EFG}$ bem como o mapeamento do traçado dos trilhos. Além disso, foram levantados e analisados dados secundários provenientes de órgãos oficiais, a exemplo do Instituto Brasileiro de Geografia e Estatística (IBGE), da Agência Nacional de Transportes Terrestres (ANTT), do Ministério da Viação e Obras Públicas, do Departamento Nacional de Estradas de Ferro, bem como da Revista A Informação Goyana.

Além disso, buscou-se expandir as perspectivas de abordagem da EFG, considerando-a enquanto rede técnica, ou seja, um objeto técnico cuja funcionalidade é determinada pelas ações políticas de alguns grupos sociais - fato que fez da ferrovia um fator relevante na produção do território goiano. Ademais, são apresentadas análises, interpretações de fatos locais e suas significações que se inserem a esse processo com foco na urbanização, nas relações socioespaciais e suas contradições que reconfiguraram o cotidiano da comunidade regional daquela época.

\section{Os trilhos: do mundo à Goiás}

O avanço técnico realizado na Europa durante o século XVIII - caracterizado, entre outros aspectos, pela mecanização dos sistemas produtivos mediada por invenções a exemplo da lançadeira volante de John Kay, o tear mecânico de Cartwright, a máquina a vapor de James Watt e a locomotiva de Stephenson - marcam o início de um intenso processo de ampliação da escala de produção de excedentes. Este processo altera, também, as relações de trabalho e o cotidiano. Balizado pelas estradas de ferro, o poder exercido no aprimoramento e na expansão de novos ideais de trabalho e produção modificaram toda a dinâmica pré-existente nos territórios alcançados. Daí o fato de que as ferrovias, assim como outras redes, procederem, simultaneamente, possibilidades de circulação e comunicação, o que demanda estratégias à manutenção ou reconstrução das estruturas de poder (RAFFESTIN, 1993).

Dessa forma, os antigos territórios feudais e coloniais vão dando lugar ao processo de modernização. De acordo com Borges (1990), a expansão das estradas de ferro no mundo, além de contribuir com o comércio - possibilitando maior fluxo dos excedentes produzidos - também gerou uma enorme demanda de trabalho. Por isso, segundo o autor, a construção de ferrovias também se tornou um negócio muito lucrativo aos interesses da Inglaterra a partir do século XVIII, que, nesse contexto, passou a difundir a técnica em outros países. O "boom" ferroviário ocorreu a partir de 1840, sendo que até 1910 - aproximadamente 80 anos após a implantação da primeira ferrovia haviam sido construídos mais de um milhão de quilômetros de trilhos em todo o mundo. A Figura 1 ilustra a evolução desse processo. 


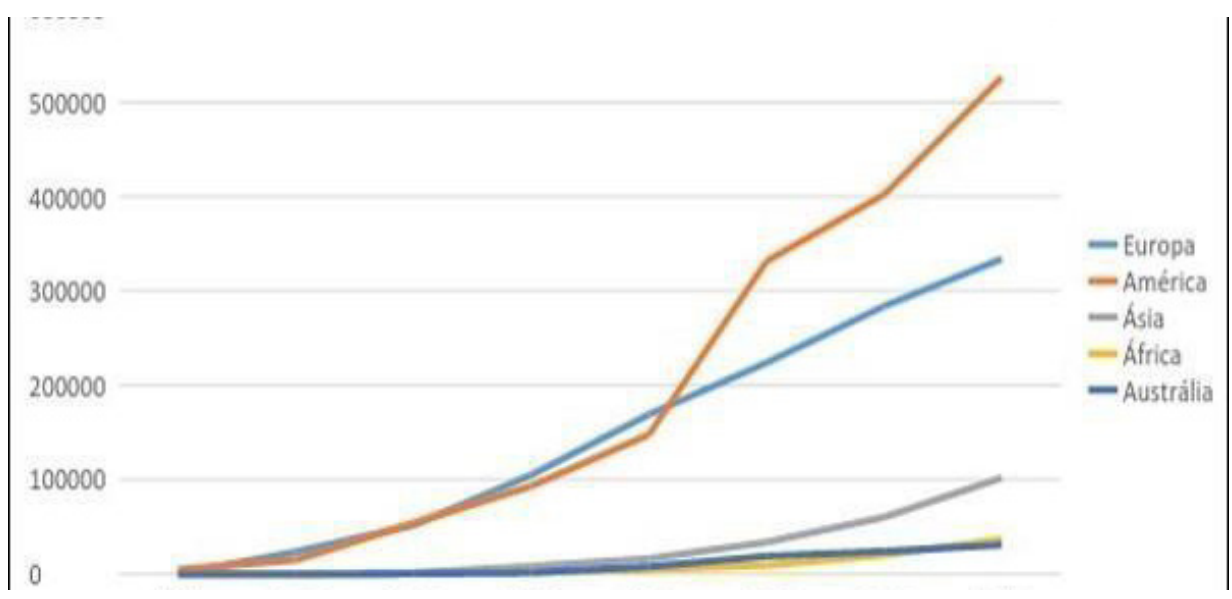

Figura 1. Evolução (em km) da rede ferroviária no mundo por continente (1840-1910). Fonte: Luxemburg (1970).

A notável expansão das ferrovias pelo mundo traduz a evolução do capitalismo em âmbito global, uma vez que as construções das estradas de ferro estavam ligadas a uma cadeia não só de produção, mas de modernização territorial (CASTILHO, 2014). Nesse sentido, ocorre a ampliação das possibilidades que propiciam fluxo de capital na região e sua área de influência. Este processo, conforme aponta Castilho (2014), tinha por base não somente a revolução industrial inglesa, mas também os ideais de igualdade, fraternidade e liberdade da revolução burguesa na França e os princípios iluministas.

Por esta razão, atrelado ao avanço técnico da modernização no espaço mundial, principalmente por meio da ferrovia, estava o ideal de progresso (CASTRO, 1993).

Associada à técnica e às máquinas, essa visão de progresso tomou tal magnitude que foi capaz de minimizar, ou mesmo anular, nas consciências de muitos contemporâneos, a dura realidade que sempre se contrapunha a ela. A ideia de um progresso inevitável, força motora da própria história, foi gradativamente introjetada em parcelas significativas da população, apesar do ônus que sua materialização impunha a essas mesmas parcelas (CASTRO, 1993, p. 3).

De acordo com Castro (1993), o avanço da modernização originou contradições, muitas vezes vencidas pelo discurso do progresso, mas que não deixam de ser característica fundamental dessa fase histórica. A construção das vias férreas significou um processo de barbárie, representado tanto pela precarização do trabalho humano quanto pela forma arbitrária pela qual se impôs a modernização nos lugares, gerando conflitos regionais tanto nos países centrais dessa produção, a exemplo do Reino Unido, EUA e outras potências, bem como na maioria dos países latinos, africanos e asiáticos, ditos periféricos (CASTRO, 1993).

Isso configurou um processo de desterritorialização, que Borges (1990) exemplifica com o caso dos camponeses europeus. Estes, segundo o autor, foram expropriados 
de suas terras de origem e integraram um largo contingente de migração para a América, onde se reterritorializaram e alteraram a dinâmica dos novos territórios, gerando, em muitos casos, conflitos nas comunidades locais.

Outra implicação desse processo, ainda de acordo Borges (1990), são as relações econômicas que se estabeleceram mundialmente, formando um regime neocolonial, caracterizado pela instalação de uma economia de dependência nos países periféricos em relação aos centrais. Dessa forma, a exploração não atendia mais às velhas práticas coloniais de extração direta dos recursos, mas assumia a forma arrojada da globalização, em um processo bem mais discreto, complexo e eficaz, sustentado pelos próprios estados que atendem as ordens liberais dos agentes que controlam o capital (BORGES, 1990).

Diante o exposto, e em conformidade às teses de Borges (1990) e Castilho (2014), o processo de formação, consolidação e expansão das infraestruturas ferroviárias nos países periféricos pode ser caracterizado como desigual. Isso porque atendeu primordialmente aos interesses dos grupos dominantes nacionais e estrangeiros que sustentavam as relações da economia dependente como marca de um mundo globalizado.

No Brasil, o processo de modernização se encaixa em um momento histórico conturbado. A queda da extração do ouro e a tomada do café como principal produto do comércio nacional demandou, conforme assinala Borges (2011), uma produção extensiva que se distanciava cada vez mais do litoral. Dado esse fator logístico, somado a política de ocupação do interior do país e as pressões externas pela modernização, em 30 de abril de 1854, no estado do Rio de Janeiro é inaugurada a Estrada de ferro Mauá, a primeira ferrovia do país (BORGES, 2011).

Devido à instabilidade política e a ausência de um plano eficaz de integração nacional, a evolução da rede ferroviária brasileira foi consideravelmente lenta em comparação a outros países de extensão territorial similar, a exemplo da Rússia, China e EUA. Assim, conforme aponta artigo elaborado na edição do I Centenário das Ferrovias no Brasil (BRASIL, 1954), a evolução da rede ferroviária no país pode ser classificada em seis períodos, conforme mostra o quadro 1 .

O quadro evidencia que o processo de gênese e ampliação das estradas de ferro no Brasil está ligado, sobretudo, às condições econômicas regionais do país naquele período. O fato é que as ferrovias surgiram primeiramente nos grandes centros urbanos da época, atendendo uma demanda crescente de circulação de serviços e comércio e só depois se expandem ao interior do país. Em 1954, estavam em operação aproximadamente 35 mil quilômetros de trilhos, distribuídos em 41 estradas de ferro (BRASIL, 1954). As Figuras 2 e 3 retratam o avanço na quantidade de pessoas e mercadorias transportadas pelas estradas de ferro nos primeiros 24 anos de sua instalação no território nacional. 
Quadro 1. Expansão geográfica das ferrovias brasileiras em seu primeiro centenário

\begin{tabular}{|c|c|c|}
\hline \multicolumn{3}{|c|}{ Expansão geográfica das ferrovias brasileiras em seu primeiro século } \\
\hline $\begin{array}{l}\text { Períodos da } \\
\text { expansão } \\
\text { ferroviária no } \\
\text { Brasil }\end{array}$ & $\begin{array}{l}\text { Crescimento } \\
\text { da via férrea } \\
\text { construída (em } \\
\quad \text { km) }\end{array}$ & Padrão de distribuição espacial \\
\hline I - (1854 a 1870) & 744 & $\begin{array}{l}\text { Distribuído em pequenas parcelas, nas províncias do RJ, } \\
\text { PE, BA, SP e MG. }\end{array}$ \\
\hline II - (1871 a 1890) & 9585 & $\begin{array}{l}\text { Expandindo-se em irradiação dos portos de Santos, Rio de } \\
\text { Janeiro, salvador e Recife as linhas iniciadas do período } \\
\text { anterior e o surgimento de novas linhas nas províncias de } \\
\text { MG, AL, CE, RS, RN, PB, PR, SC e ES. }\end{array}$ \\
\hline III - (1891 a 1910) & 11352 & $\begin{array}{l}\text { Expansão das linhas dos estados de SP, RJ, MG, RS; às } \\
\text { ligações anteriores do PR e SC e dos estados de AL, PE, } \\
\text { PB e RN. Prolongamento das linhas surgidas no período } \\
\text { anterior e aparecimento de novas linhas no ES e PA e em } \\
\text { outras unidades da federação. }\end{array}$ \\
\hline IV - (1911 a 1930) & 11152 & $\begin{array}{l}\text { Irradiou as redes ferroviárias paulista, fluminense, mineira, } \\
\text { sul- riograndense, paraná-catarinense, baiana e nordestina; } \\
\text { surgem novas linhas no MA, PI, GO, MG, PÈ e BA. }\end{array}$ \\
\hline V - (1931 a 1954) & 4539 & $\begin{array}{l}\text { A partir do Plano Geral de Viação Nacional (1934) as } \\
\text { construções de linhas férreas passam a ter como principal } \\
\text { objetivo as "ligações ferroviárias", articulando as várias } \\
\text { estradas buscando formar a grande rede ferroviária nacional. } \\
\text { (integração entre bitolas) }\end{array}$ \\
\hline
\end{tabular}

Fonte: Brasil (1954).

Nota: dados organizados pelos autores.

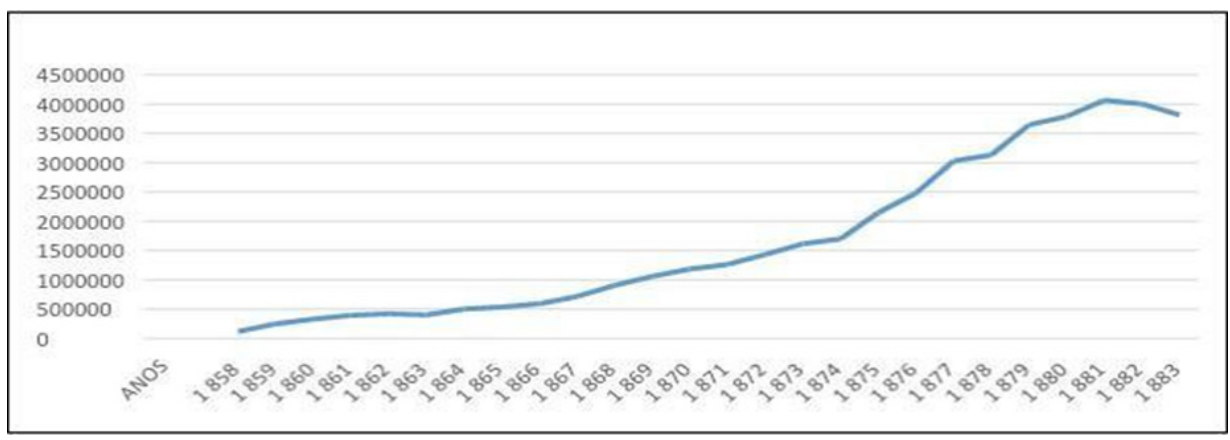

Figura 2. Passageiros transportados por estradas de ferro no Brasil (1858-1883).

Fonte: Estatísticas históricas do Brasil (1988). Nota: dados trabalhos pelos autores. 


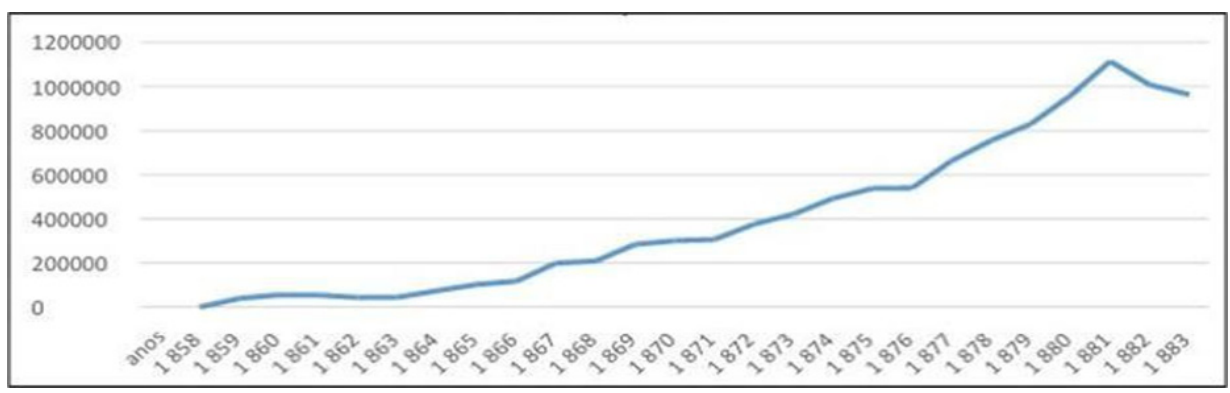

Figura 3. Volume de mercadorias transportadas por estradas de ferro no Brasil (1858-1882). Fonte: Estatísticas históricas do Brasil (1988). Nota: dados trabalhos pelos autores.

Ainda que o recurso fosse pouco explorado, o crescente uso do transporte ferroviário demonstra sua eficácia para a época, mesmo que ainda não estivesse sido estabelecida uma rede de integração nacional. Apesar da posição estratégica e do potencial produtivo de Goiás, somente em 1912 são construídos os primeiros trilhos no território goiano. Conforme defende Castilho (2014), a Estrada de Ferro Goiás (EFG) surge como forma de atender as necessidades locais de modernização, mas está ligada, sobretudo, à pressão externa exercida pelos empresários do Sudeste brasileiro e pelo capital internacional no país.

Ao justificar o processo de construção das ferrovias interioranas no país, Galvão (1996) cita um trecho do discurso elaborado pelo engenheiro Ramos de Queiroz apresentado ao senado em 1882, contendo sua intenção quanto ao plano ferroviário nacional e afirmando essa mesma tese:

Franquear os tesouros ocultos no coração do Brasil aos povos de todas as nações do globo; disseminar a civilização pelo interior de nosso país; economizar o tempo gasto em percorrer as distâncias, de harmonia com os altos interesses políticos e estratégicos, e a percepção de que a grandeza deste país está, antes de tudo, na integridade de seu território (QUEIROZ, 1882 apud GALVÃO, 1996, p. 47-48).

Considerando a influência externa de construção da ferrovia, sua posição significou, sob uma perspectiva econômica, a valorização dos lugares, uma vez que esta é influenciada não somente pela localização e/ou a produção, mas também pela circulação (ARROYO, 2015). Nesse sentido, a Figura 4 mostra o traçado da antiga Companhia Mogiana de Estrada de Ferro até a cidade de Araguari (MG), de onde foi construída a ferrovia em direção ao território goiano.

Conforme mostra a Figura 4, a integração da rede ferroviária expressa o sentido da atribuição de valor pela relação estabelecida com o Triângulo Mineiro e a região de Campinas (SP), que além de ser uma importante área econômica, possibilitava acesso aos portos do Sudeste brasileiro.

A Figura 5, por sua vez, mostra a evolução do processo de expansão da Estrada de Ferro Goiás no território goiano. 


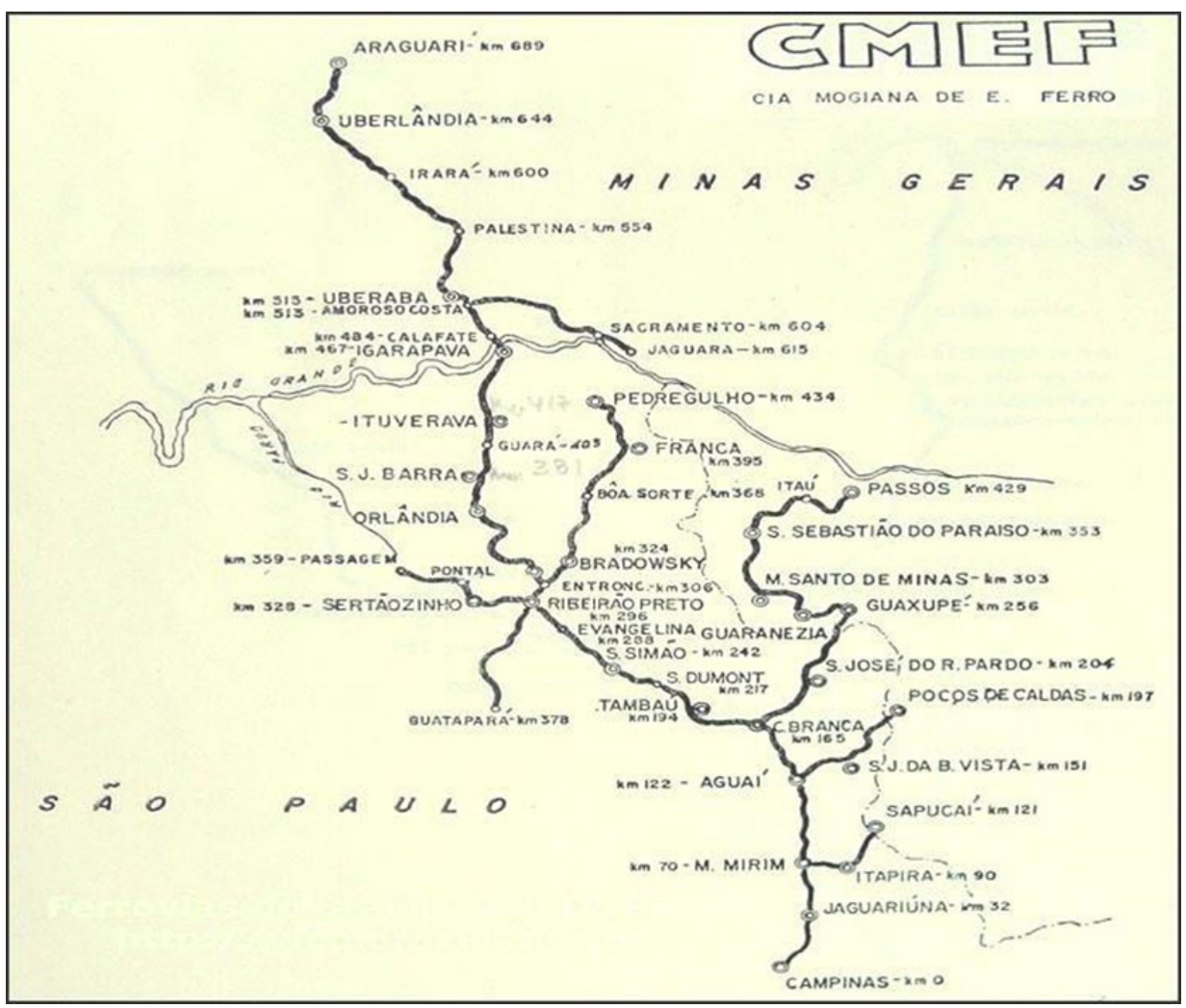

Figura 4. Companhia Mogiana de Estrada de Ferro.

Fonte: DNEF (1970).

Isso significa que a Estrada de Ferro simbolizou para o estado de Goiás mais que uma simples infraestrutura de circulação. Ela foi a ligação com a metrópole e tudo o que esta pode representar. Ao destacar a influência da EFG para o estado, Arrais (2016, p.18) afirma que ela "fundou municípios; alterou a estrutura fundiária; influenciou a cultura por meio da modernização; e provocou mudanças no mercado de trabalho". Em outros termos, pode-se afirmar que a estrada de ferro alterou significativamente a dinâmica do território goiano, uma vez que viabilizou o advento da modernização territorial (CASTILHO, 2016).

Entretanto, baseados em Santos (1996), não pretendemos conter a análise do processo de modernização somente de forma verticalizada, pois ela atinge também um sentido horizontal na reprodução da vida cotidiana nos lugares. É sob essa perspectiva de horizontalidade na produção do território que o presente estudo é baseado, mas com a atenção de não desconsiderar as influências verticais das instituições. 


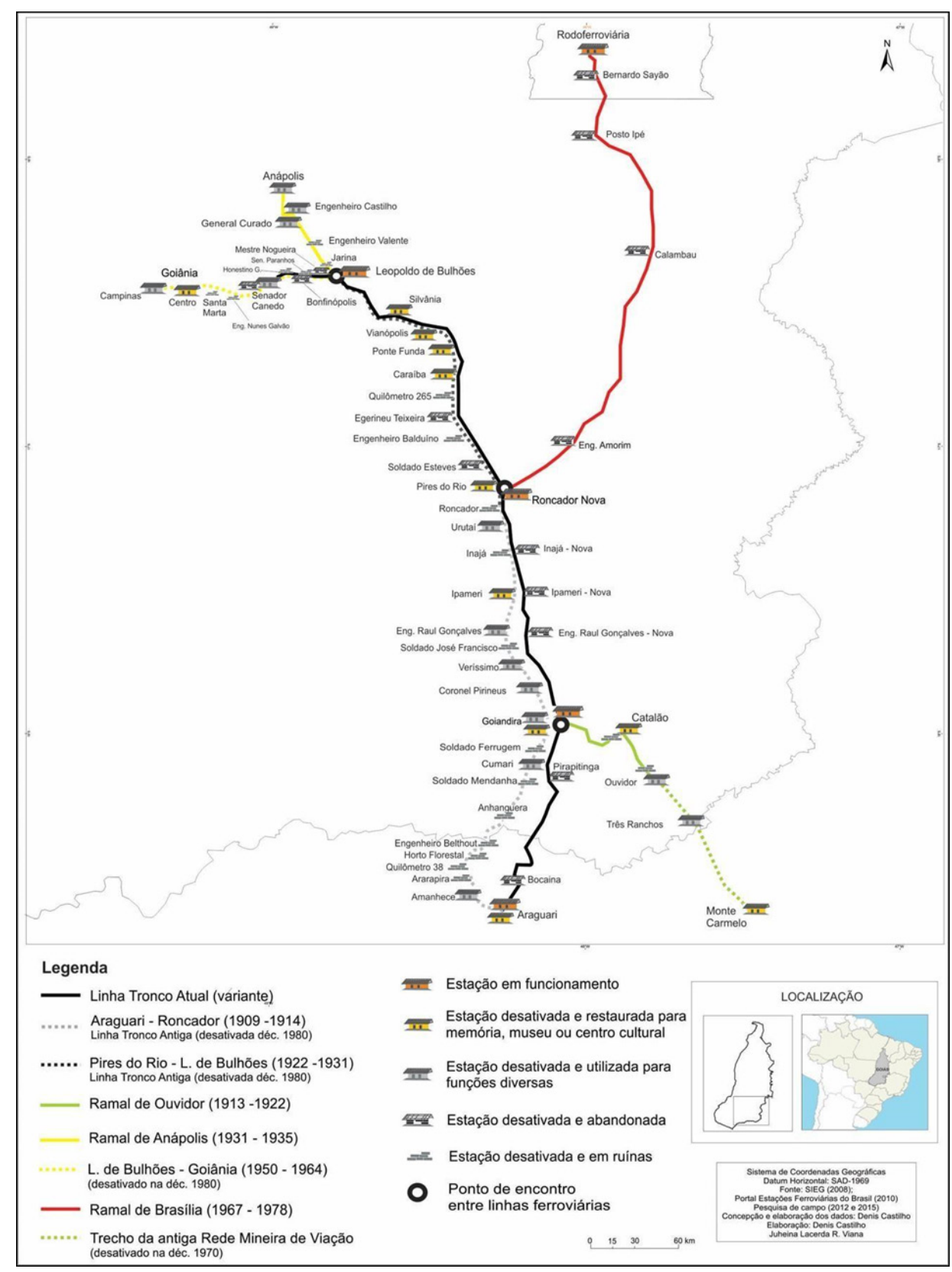

Figura 5. Evolução e alteração do traçado da Estrada de Ferro Goiás (1909-2015)

Fonte: Castilho (2014). 


\section{A modernização chega de trem: urbanização e transformações no cotidiano}

De forma relativamente lenta e gradual, conforme exposto na Figura 6, os trilhos da EFG foram adentrando o território goiano a custo de árduo trabalho para sua construção. O até então "distante" estado de Goiás, dominado pelo coronelismo e habitado por sujeitos de vida simples, com a chegada da ferrovia passa a se integrar com um modelo de produção econômica e social que já havia propiciado revoluções em favor da classe burguesa em várias regiões do mundo, tal como ressalta Borges (1990).

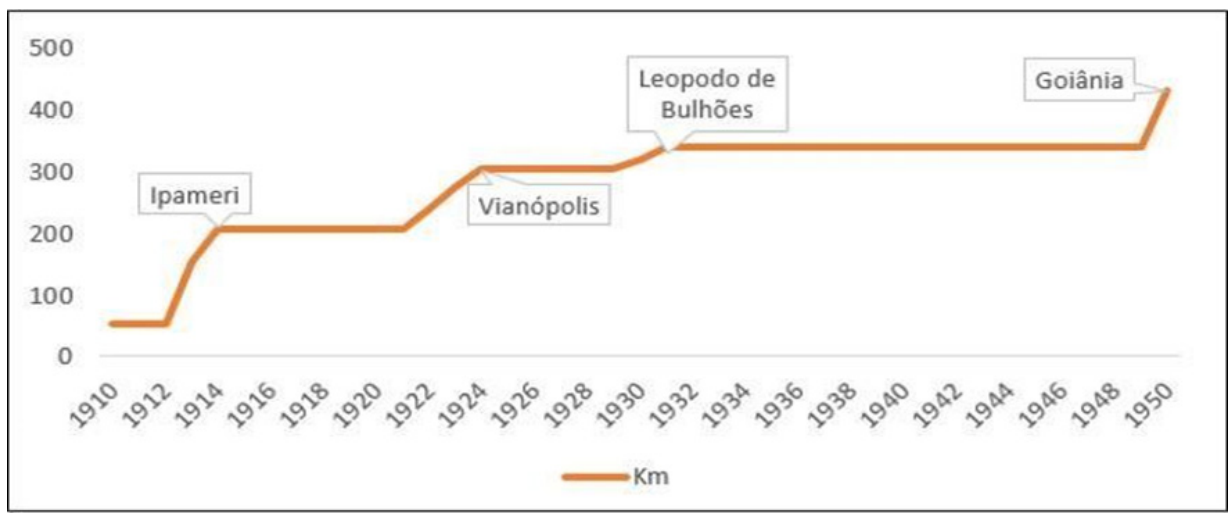

Figura 6. Evolução (em km) da via permanente da EFG (1910-1950)

Fonte: Portal das estações ferroviárias do Brasil (2010).

A modernização trazida à Goiás por meio da estrada de ferro demonstra uma nova escala às possibilidades humanas perante o tempo e o espaço. Não é de se espantar, conforme aponta Brandão (2005) em relação ao caso de Ipameri, a euforia gerada pela chegada do trem no estado. Sua velocidade quase constante, atravessando rios e cortando morros indo em direção ao desconhecido, despertava, em alguns, a curiosidade, mas também, em outros, o medo (BRANDÃO, 2005). Fato é que, no início do século XX, a implantação e funcionamento da EFG em Goiás alteraram não somente a organização do espaço regional, mas também o cotidiano nos lugares por onde passavam os trilhos.

Esse processo pode ser mais bem compreendido tendo em vista o fato de que, tal como defende Santos (1996), o espaço geográfico ser formado por um conjunto de fixo e fluxos.

Os elementos fixos, fixados em cada lugar, permitem ações que modificam o próprio lugar, fluxos novos ou renovados que recriam as condições ambientais e as condições sociais, e redefinem cada lugar. Os fluxos são um resultado direto ou indireto das ações e atravessam ou se instalam nos fixos, modificando a sua significação e o seu valor, ao mesmo tempo em que, também, se modificam (SANTOS, 1996, p. 38). 
Nesse sentido, o caso da Estrada de Ferro em Goiás é emblemático: os fixos correspondem aos municípios e às estações; os fluxos, aos serviços, às mercadorias, pessoas, informações, etc. É diante dessa concepção que entendemos a relação entre os lugares e o território. Se a partir do lugar afetivo da vivência cotidiana constitui-se a significação do espaço geográfico enquanto meio para as relações sociais, as possibilidades de circulação que a estrada de ferro carrega transformam o cotidiano e faz da estação uma centralizadora da reprodução da modernização. Para tanto, ela assume uma posição fixa, mas ao mesmo tempo representa o fluxo, afirmando uma multiterritorialidade (Haesbaert, 2001), ou seja, ora figura como o território-rede do capitalismo, ora o território-zona agrário, ora também como ambos. A Figura 7 demonstra o contraste na paisagem do tradicional carro-de-boi e a moderna estação ferroviária.

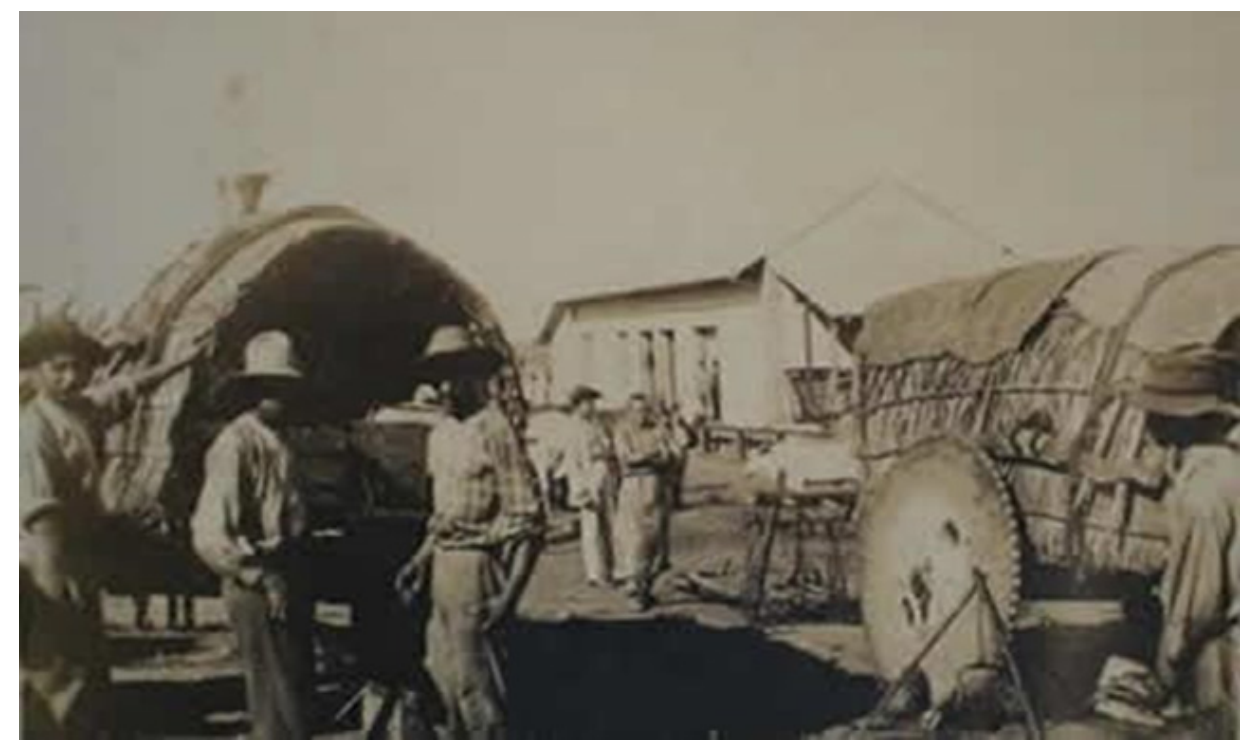

Figura 7. Tropeiros acampados em derredor da primeira Estação Ferroviária de Ipameri, 1913. Foto: Costa et al (2017).

Essa coexistência de elementos tradicionais e modernos passa a disputar espaço regional, muito embora era visível a proeminência dos elementos símbolos da modernização. Isso porque, conforme aponta Castro (1993), a ideia do progresso ligado às relações capitalistas, como um caminho da própria história, torna sua expansão quase hegemônica. Essa tese foi sustentada pelos próprios intelectuais que residiam na região nessa época e exerciam forte influência na formação da opinião coletiva.

De acordo com Brandão (2005), o trem trouxe um novo projeto de cidade, idealizado pelos políticos locais, que buscavam afastar a imagem de campo e conferir uma característica urbana. Também, a autora acrescenta que é necessário também olhar a cidade buscando "encontrar e construir significados, a partir do trem. Daí a necessidade 
de se refletir sobre o impacto causado pela ferrovia num lugar do sertão goiano, sobretudo nas mentalidades sociais e coletivas" (BRANDÃO, 2005, p. 89).

A distância entre as estações no leito da ferrovia não ultrapassava 20 quilômetros, pois as caldeiras das locomotivas (Maria Fumaça) demandavam abastecimento de água em períodos curtos, justificando o povoamento em seu leito (ARRAIS, 2016). Essa condição espacial em um primeiro momento promove habitações em conjuntos de casas construídas de forma precária pela empresa gestora ao longo do trecho ferroviário, conhecidas como "turma" (INÁCIO, 2003). Essas habitações serviam como base para a manutenção dos trilhos e das locomotivas. Posteriormente é cercada por sertanejos que chegavam em carros de boi e se assentam em busca de compra ou venda de mercadorias.

Esse processo, no entanto, não foi uniforme. As estações situadas em melhores sítios, com maior possibilidade de acesso a recursos hídricos, áreas planas e solos férteis e a aproximação com centros urbanos já consolidados, foram priorizadas na distribuição populacional ao longo da ferrovia. Essa situação, conforme indica Coelho (2011), originou três grupos de estações com características comuns, conforme exposto no quadro 2 .

Quadro 2. Grupos de estações ferroviárias que se desenvolveram de forma semelhante ao longo da EFG

\begin{tabular}{|c|c|c|}
\hline $\begin{array}{l}\text { Algumas estações que } \\
\text { permaneceram de acordo com o } \\
\text { previsto (manutenção dos trens) }\end{array}$ & $\begin{array}{l}\text { Algumas estações que tiveram } \\
\text { seus entornos povoados e se } \\
\text { tornaram distritos vinculados aos } \\
\text { municípios }\end{array}$ & $\begin{array}{c}\text { Algumas estações que } \\
\text { conseguiram independência } \\
\text { política e se transformaram em } \\
\text { municípios }\end{array}$ \\
\hline Soldado ferrugem & Veríssimo & Catalão \\
\hline Coronel Pirineus & Egirineu Teixeira & Urutal \\
\hline Raul Gonçalves & Ponte funda & Pires do rio \\
\hline Janira & Caraíba & Vianópolis \\
\hline Padre Silvino & & Leopoldo de bulhøes \\
\hline
\end{tabular}

Fonte: Coelho (2011)

Uma ilustração da influência do meio na ocupação das áreas margeadas pela EFG pode ser observada na figura 8 . Feita a distribuição da localização de algumas estações no perfil topográfico, observa-se, por exemplo, uma concentração de núcleos urbanos nos antigos pontos de parada do trem de ferro de Egerineu Teixeira até Janira. O relevo com baixa declividade e a posição geográfica - político e economicamente favorável, dada a localização entre Goiânia e Brasília - são fatores que devem ser considerados no desenvolvimento urbano na região servida pelos trilhos durante o funcionamento da ferrovia. 
Perfil topografico e importantes estações (1950) da Estrada de Ferro Goiás

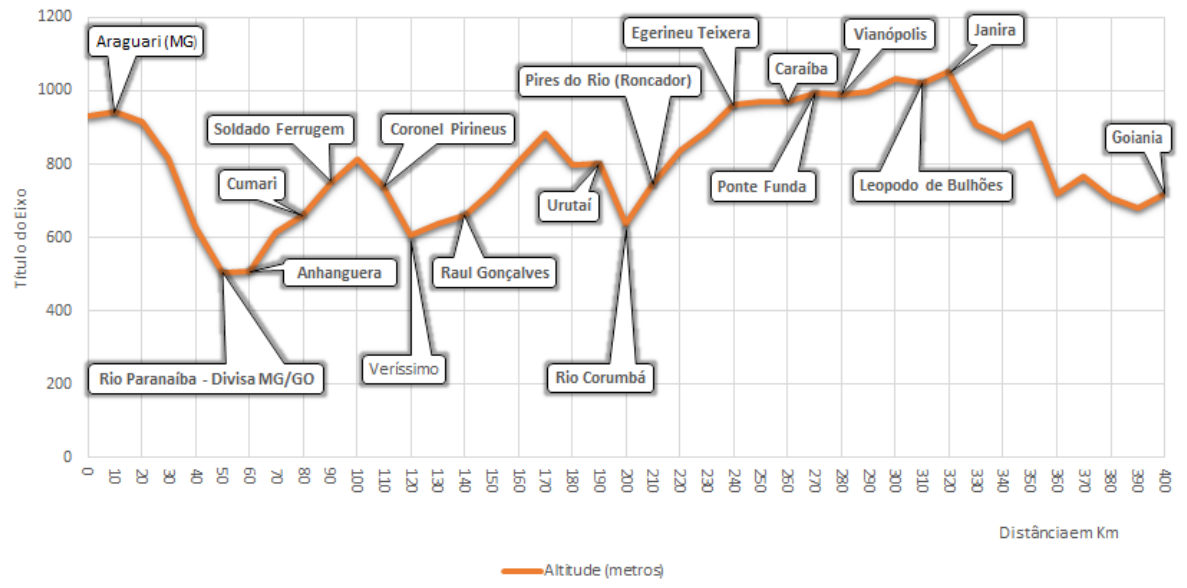

Figura 8. Perfil topográfico e importantes estações da EFG (1950).

Fonte: Portal das estações ferroviárias do Brasil (2010).

Outra mudança conjuntural advinda da ferrovia foi a promoção da primeira relação de trabalho moderno nessas terras (INÁCIO, 2003). Essa relação, porém, não poderia ser considerada menos árdua que a do campo no que se trata de manutenção dos dormentes e locomotivas. A Figura 9 retrata o trabalho de abastecimento de uma Maria Fumaça com lenha, demonstrando o grande consumo desse tipo de combustível que os trens necessitavam para sua locomoção - o que também ocasionou grande desmatamento na região.

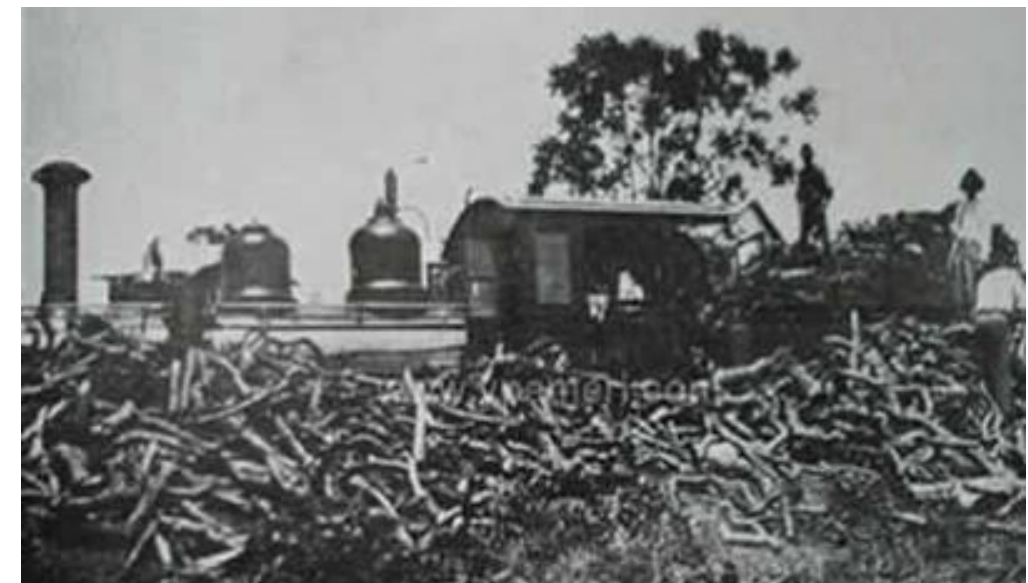

Figura 9. Abastecimento de lenha para Maria Fumaça em Ipameri (1926). Foto: Costa et al (2017). 
Vale ressaltar que, a partir do advento da ferrovia, outros elementos de modernização chegam progressivamente. Na cidade de Ipameri, por exemplo, foi instalada uma central hidroelétrica em 1914. Também se destaca a construção de pontes, estradas de rodagem, a chegada do telégrafo e a impressa na cidade. Porém, o maior fator de efetivação da modernização são os imigrantes, pois trazem em suas "bagagens" novos hábitos que passam a reconfigurar o cotidiano regional. Além da centralidade econômica das cidades goianas servidas pelos trilhos, há de se destacar, portanto, o aumento populacional e o papel dos migrantes estrangeiros vindos de países como Espanha, Síria, Líbano, Portugal, Alemanha, etc. (BRANDÃO, 2005).

Brandão (2005) assinala que, em 1920, haviam 330 estrangeiros em Ipameri dedicando-se às atividades do setor secundário e terciário, a exemplo de charqueadas, fábricas de banha, máquinas de beneficiamento de arroz e comércio varejista. Também serviam como mão-de- obra qualificada à Companhia Construtora da Estrada de Ferro. Essa dinâmica demográfica, que incentivava o aumento da produtividade na região, recebeu forte apoio e até incentivos da classe política na região, defende a autora. Confirma essa tese, segundo Brandão (2005), o fato de que foram propostas várias medidas para incentivar a ocupação das terras na região, tal como noticiado no Jornal Ypameri, de 18 de setembro de 1927.

Acenar aos trabalhadores com doação dessas terras, ou venda por preços módicos, criar prêmios para os maiores plantadores de produtos destinados à indústria, isentar de impostos os fazendeiros que localizarem imigrantes em suas propriedades, tornar excessivo os impostos sobre terrenos não cultivados, bater-se pela cultura de algodão em alta escala e favorecer a indústria que se propunham a montar estabelecimentos têxteis no Estado, não lhes cobrando impostos por uma dezena de anos. (O Ypameri, 1927 apud, BRANDÃO, 2005. p. 75)

Como consequência dessa política de incentivo, ainda de acordo com Brandão (2005), colônias inteiras de migrantes vieram para a região, oriundas principalmente do Sudeste do país e até do exterior. Na cidade de Ipameri, destaca-se a trajetória dos sírios que, segundo Costa et al (2017), formaram a maior colônia recebida em número de famílias. Os "turcos", como eram chamados, inauguram o comércio na cidade, em um primeiro momento como "mascates", pois viajavam na região em tropas de animais comprando, vendendo e trocando produtos. Posteriormente com melhores condições, eles conseguiram estabelecer suas próprias lojas que geralmente dispunham de artigos de utilidade doméstica, tecidos, armazém de secos e molhados, além de se dedicarem a indústria de beneficiamento de arroz, café e laticínio (COSTA ET AL, 2017).

$O$ fato é que o fluxo de imigrantes influenciou sobremaneira a formação de famílias tradicionais na região. Daí ser comum o fato de alguns cidadãos eméritos desses municípios possuírem sobrenomes de origem estrangeira. Ademais, também é possível observar atualmente nessas cidades vários logradouros que carregam sobrenomes de famílias estrangeiras, a exemplo das Avenidas Dr. Nadin Saud, Maria Guiotti e Michelili Santinoni, em Pires do Rio. 
Além do significativo fluxo migratório durante o período de construção dos trilhos, em momentos que sucederam a inauguração da ferrovia também houve a chegada de estrangeiros na região. Por este motivo, os imigrantes tiveram participação relevante no adensamento populacional da região, influenciando assim a urbanização e as demandas que ela agrega (comércio, saúde, educação, política etc.).

Brandão (2005) ressalta o fato de que os imigrantes, assim como a classe de influência política, passaram a impor demandas civilizatórias nesses novos núcleos urbanos. Houve para tanto um projeto de cidade modernizada, que tem como grande marca a higienização do espaço. As primeiras casas que surgiram próximas às estações habitadas pelos sertanejos locais, que se estruturavam como pequenos sítios onde se criavam porcos, galinhas e cavalos, passaram a ser proibidas dentro das cidades. Esse projeto tomou tamanha dimensão que, em Ipameri, por exemplo, havia um delegado de higiene para garantir o cumprimento dos padrões. Buscou-se com o ideário de civilização moderna constituir uma aproximação, ao menos simbólica, do modo de vida nas grandes cidades. Assim foram justificadas propostas de intervenções urbanas, tal como destaca Brandão (2006) ao expor o pensamento da classe de influência local naquela época:

Civilizar significa embelezar a cidade, torná-la higiênica, afastar a mendicância, as mulheres "de vida alegre", não mais comporta a presença do chiqueiro, matadouro, carro de boi e cemitério convivendo com a modernidade; tudo isso tem que estar afastado do chamado "perímetro urbano". (BRANDÃO, 2006, p. 76)

Os trabalhos manuais dos camponeses perdiam respaldo ao passo que as instituições modernas ganhavam força na região. Cite-se, por exemplo, o caso dos abatedouros comuns que foram substituídos pelos açougues - sendo estes, a partir de então, o único meio autorizado formalmente para o comércio de carne em Ipameri (BRANDÃO, 2005). Importa ressaltar que essas medidas vislumbravam, segundo Brandão (2005), a necessidade que se impôs de desconstruir a imagem do "jeca" associada ao goiano.

Além disso, tamanho foi o rigor de imposição da modernidade que até a arquitetura de casas comuns que seriam construídas eram vistoriadas para se adequar aos padrões da modernidade. Quanto a estrutura da cidade, se prezava por ruas largas, praças e prédios quem geralmente portavam símbolos de poder. Destacam-se as edificações estatais, com sua arquitetura arrojada, a exemplo da Agência do Banco do Brasil em Ipameri (Figura 10).

Com o tempo, foram sendo construídas outras infraestruturas, a exemplo da rede de esgoto, energia elétrica e iluminação pública. Esses benefícios, no entanto, estavam restritos a uma minoria local que possuíam maior poder aquisitivo. Os privilégios também se estendiam aos melhores vagões nos trens e às possibilidades de participação política. A modernização, concebida de forma naturalizada, foi, na verdade, seletiva. Nas palavras de Castilho (2010),

uma naturalização do fenômeno (modernização) que coloca a expansão do modo de produção capitalista como algo necessário ao "progresso social" e 
considerando a pobreza, a fome e a segregação como resultado do atraso, ou como o avesso das sociedades modernizadas [...]. A miséria não representa o reverso de um processo econômico, nem expressa atraso de um território, mas a contradição do tipo de modernização que vem sendo (re)produzida em países como o Brasil (CASTILHO, 2010, p. 12-13).

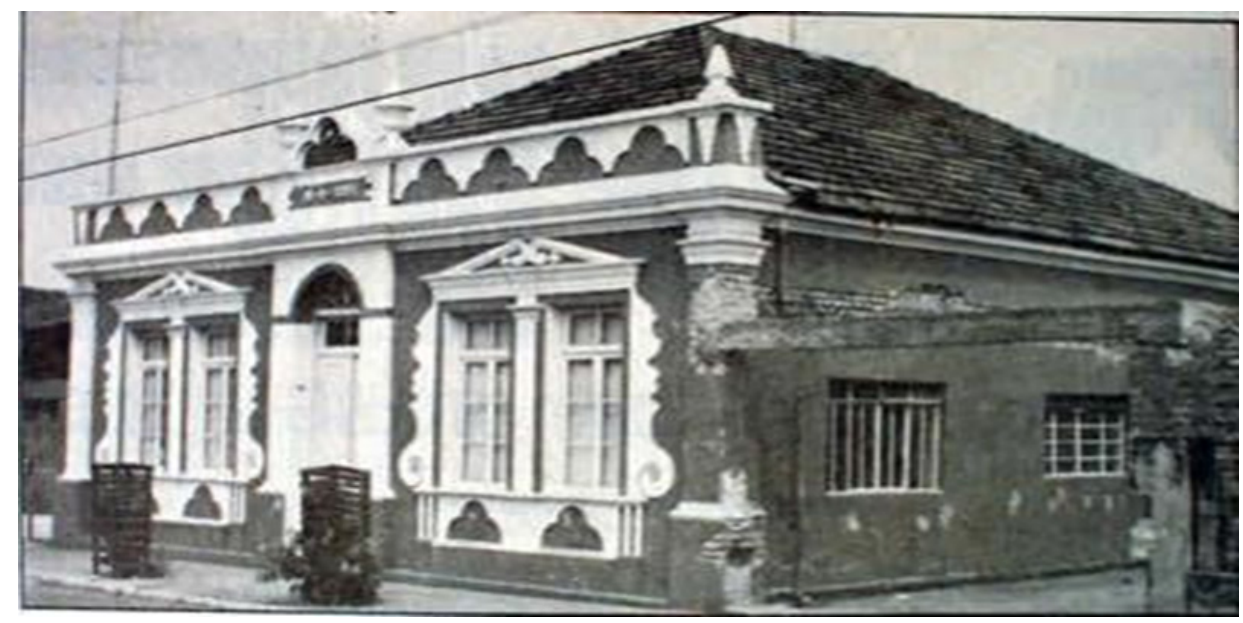

Figura 10. Primeira agência do Banco do Brasil em Goiás (Ipameri) - 1921 Foto: Costa et al (2017).

Outro aspecto relacionado aos efeitos da EFG diz respeito à ampliação da influência das ações estatais no território goiano, tanto durante a Primeira República (1889-1930) quanto no regime do Estado Novo (1930-1945). Segundo Chaul (1997, p. 149) "a modernidade para os arautos de 1930 consistia no progresso do Estado, por meio do desenvolvimento da economia, da política da sociedade e da cultura". Ao versar sobre a cultura cívico-escolar católica e desfiles patrióticos no Brasil do início do século XX, Bencostta (2014) indica uma aproximação entre Estado e Igreja, evidenciado pelo trecho da Pastoral Coletiva do Episcopado:

Em comemorar com deslumbrantes, (...), o amanhecer de nossa vida nacional, quando o tempo the confere consagração secular, se empenha a Igreja e o Estado, isto é, toda a Nação Brasileira. Com efeito, para oferecer a sociedade hodierna e aos porvindouros, lições vivas de acendrado patriotismo, muito aproveita evocar, recompor e aviventar a sociedade brasileira d'outrora com seu espírito de fé e exemplos de virtudes cristãs, seus galhardos feitos militares e amor à paz e ao progresso, sua dedicação à imunidade do país e seu fraternal comércio com as nações estrangeiras. (PASTORAL, 1922, p.3)

Esse momento histórico refletiu diretamente no cotidiano regional, conforme retrata a Figura 11, expondo o momento em que foi realizado um evento cívico de juramento à bandeira em uma praça pública na cidade de Ipameri, no ano de 1928. 


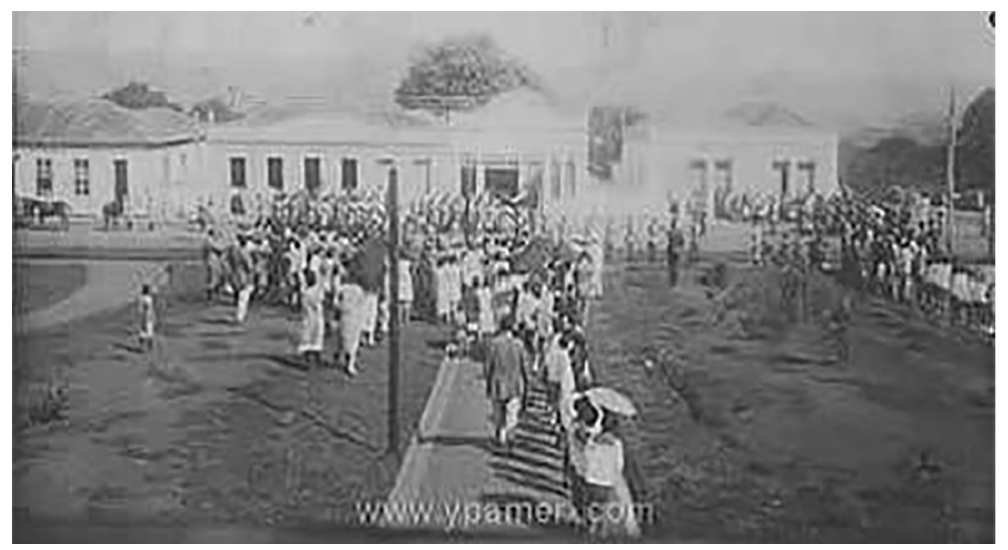

Figura 11. Evento cívico na praça da liberdade em Ipameri (1928).

Foto: Costa et al (2017).

Com o passar dos anos, intensifica-se amplia-se na região o processo de modernização, uma vez que ganhava forma em âmbito nacional com a entrada cada vez maior de empresas e capital estrangeiro, conforme relata Borges (1990). A urbanização é consolidada, os meios técnicos se tornam cada vez mais complexos, a produção se diversifica por meio das pequenas indústrias, o comércio formal é estabelecido e assim se firmam novas relações de trabalho moderno nos lugares. Tais avanços técnicos, contudo, necessitavam do consumo para assegurar sua evolução.

Nesse sentido, segundo Medeiros (2009), o cinema foi uma grande ferramenta para a propagação do ideal de modernidade nos séculos XIX e XX. Em Goiás, isso pode ser comprovado pelo fato de, em 1950, terem sido inauguradas salas cinematográficas em Ipameri e Catalão, cidades servidas pela EFG (Figura 12).
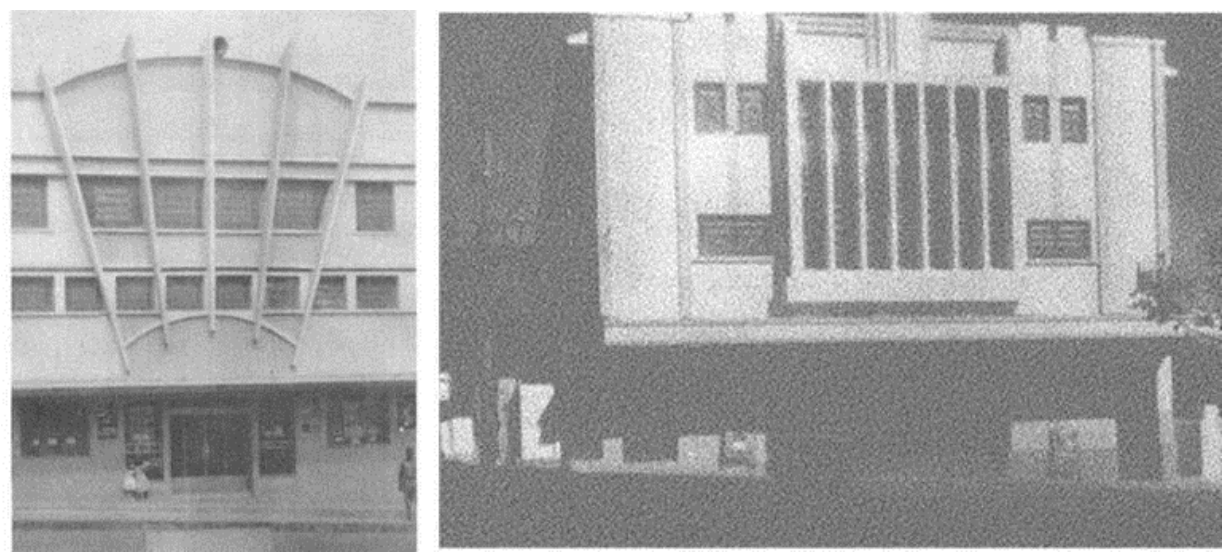

Figura 12. Cineteatro Estrela de Ipameri e Cineteatro Real de Catalão (1950), respectivamente. Fonte: Brasil (1958). 
Podemos destacar também a influência do rádio que trazia informações locais e outras vindas da capital nacional, entre uma propaganda e outra - geralmente política ou comercial - se transmitiam novelas, jogos de futebol, músicas.

O rádio, assim como outros meios de comunicação (jornais e revistas) existentes
em Goiás na década de 30 e 40 contribuiu, à sua maneira, para a formatação
de um ambiente propício à efetivação dos interesses do Estado. Foi, entre
tantas outras estratégias criadas pelo Estado nacional, um dos meios por onde
divulgava constantemente as suas intenções. (MARQUES 2009, p. 10)

Essas transformações nas ordens espacial e social que induzem um condicionante a modernização, contudo, não resulta nessa região a um modo de vida agitado como o das metrópoles (BRANDÃO, 2005). Segundo a autora, o ritmo de vida sertaneja é alterado, mas não muda totalmente. Por isso cita a narrativa de Monteiro Lobato ao falar do estilo da população local na seguinte perspectiva: "mesmeiros", que todos os dias fazem as mesmas coisas, dormem o mesmo sono, sonham os mesmos sonhos, esperam o mesmo correio (...) lamuriam do presente e pitam longos cigarrões de palha, matadores do tempo (LOBATO, 2004 apud BRANDÃO, 2005, p. 47).

Ainda em referência aos escritos de Monteiro Lobato, Brandão (2005, p. 47) versa sobre as cidades do Sudeste Goiano associando-as a essa "mesmice do dia-adia", que o curso do tempo sofria interrupções apenas pelo badalar do sino da igreja, o estalar das palmas do "compadre" para uma visita e, sobretudo, pelo apito do trem, que constituía uma grande novidade. A Figura 13 reluz o momento em que a Maria Fumaça chega à estação sede da Estrada de Ferro Goiás na cidade de Araguari, em Minas Gerais, e no centro de Pires do Rio, em Goiás. É possível observar a movimentação de pessoas evidenciando a centralidade exercida pela estação no horário de chegada do trem.
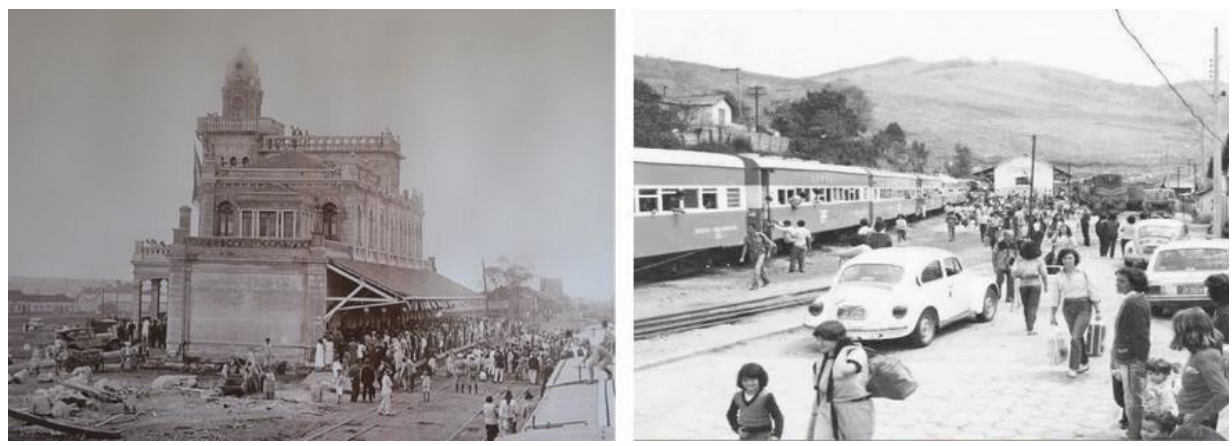

Figura 13. Momento da chegada do trem nas estações da EFG em Araguari-MG (década 1920) e Pires do Rio-GO (s.d.), respectivamente.

Fontes: Acervo Histórico de Araguari e Histórias das Histórias de Pires do Rio, Facebook (acesso em mai. 2017).

Tamanha foi a influência da Maria Fumaça no cotidiano local que Ferreira (2011) atribui à passagem do trem a função de relógio, tal como no caso de Pires do Rio. 
A regularidade dos trens, na época, tornou-se um sinalizador para a vida da população, transformando a estação em um relógio público, por meio dos longos apitos das locomotivas. (...). Para os que corriam até a estação, horário de discutir negócios, de colher informações gerais, de receber jornais e correspondências, de encontrar ou se despedir de pessoas amadas, de apreciar a chegada de meretrizes. No período noturno, as horas eram sinalizadas pelo guarda-noite, mediante batidas fortes numa barra de trilho, das seis da tarde às seis da manhã: tantas pancadas quantas as horas (...). Esse ritual se manteve sem alteração, até 1935, aproximadamente (FERREIRA, 2011, p. 21).

Nogueira (1977) também ressalta a relação entre o trem e as manifestações associadas ao sentimento coletivo. Segundo o autor, "enquanto com uma das mãos o maquinista acionava a corda do apito a golpes sucessivos, com outra acenava a todos, numa amável e efusiva saudação" (NOGUEIRA, 1977, p. 63). Além disso, ainda de acordo com o autor, eram marcantes os momentos dos longos apitos das locomotivas nas oportunidades festivas bem como seus períodos de silêncio nos momentos religiosos ou de luto local.

Além disso, a música é outro aspecto que caracteriza a influência dos trilhos na vida das pessoas que residiam no interior. A canção "mala amarela" - composta por José Caetano Erba e consagrada na interpretação de Lourenço e Lourival - possibilita muitas reflexões nesse sentido. A narrativa aborda a trajetória de um corajoso jovem que abandona o campo de "mala e cuia" por meio do trem em busca dos deslumbres que acreditava encontrar na grande cidade, mas se depara em uma situação difícil, completamente diferente do que esperava e decide então retornar a casa dos pais. $\mathrm{O}$ sucesso dessa música nas rádios da época demonstra a identificação da classe popular com esse movimento estabelecido pela relação entre a grande cidade e o sertão mediada pelo trem.

Com o passar dos anos, no entanto, os laços que as populações das cidades tinham com os trilhos aos poucos foram se exaurindo. Isso porque, semelhantemente ao processo de sua implantação, forças políticas regionais decidiram o futuro dessa rede. A ferrovia foi desativada e, com isso, teve início uma série de implicações sociais. Os cinemas foram fechados, a arquitetura das casas dos primeiros imigrantes do século, assim como as pontes e muitas estações ficaram em ruínas. Paira no discurso de muitos contemporâneos, principalmente entre aqueles que trabalharam na ferrovia, um sentimento de viuvez quando falam do assunto.

A entrevista realizada com o ex-ferroviário Sebastião da Silva, publicada pela revista UFG no Dossiê Ferrovias (2011, p. 151), exprime a síntese da percepção de toda uma classe que dedicou boa parte de sua vida aos trilhos: "Acredito que alguns trabalhadores ferroviários, colegas meus, morreram de tristeza perante o abandono do transporte ferroviário havido em Goiás".

\section{Considerações finais}

As discussões aqui apresentadas, longe de esgotar a geografia e a história da ferrovia em Goiás, reforça a ideia que os trilhos representaram bem mais que apenas 
um meio de circulação e de modernização ao território goiano. Essa rede de transporte foi trabalho, esperança, alegria, angústia, amor, poder, mudança, arte, informação, conhecimento e tantos outros adjetivos que expressam a complexidade da relação dos sujeitos com seus lugares.

Fica evidente o modo como o processo de modernização, por meio das redes técnicas, influi na produção dos territórios. O ideal de progresso "dissolvido" na fumaça das locomotivas, que para muitos representava o tão sonhado futuro próspero, foi, de fato, o símbolo de importantes transformações para alguns, mas também de frustração para outros que visualizavam nas antigas estações a permanência de uma rotina que se foi.

Significativa parte dessas transformações está ligada a um contexto políticoeconômico que transcende a determinação local. A primeira grande guerra na Europa, a crise de 1929 desencadeada nos EUA, a revolução do Estado novo em 1930, a Segunda Guerra Mundial, assim como outros eventos históricos mudaram a direção dos rumos políticos no Brasil e no mundo e ecoaram seus efeitos também nos sistemas de transportes. O fator político adotado após a construção de Brasília, que caracterizou a refuncionalização dos trilhos, fez com que eles deixassem de servir a dinâmica dos fluxos das cidades - que ficaram por conta das rodovias - e ficassem submetidas à economia agroexportadora e à importação de itens industrializados. Isso, no entanto, não pode legitimar o esquecimento daquela que foi uma "nova era" em Goiás.

$* * *$

Este artigo é fruto de pesquisa desenvolvida no âmbito do projeto "A rede ferroviária em Goiás: análise e mapeamento da dinâmica econômica regional e da urbanização entre 1911 e 2014" (Chamada Universal-MCTI/CNPQ No 14/2014).

$* * *$

\section{Referências}

ARRAIS, C. A.; OLIVEIRA, E. C.; ARRAIS, T. A. O século XX em Goiás: o advento da modernização - Goiânia: Cânone Editorial, 2016.

ARROYO, M. M.; CRUZ, Rita de Cássia. Território e Circulação: a dinâmica contraditória da globalização. 1. ed. São Paulo: Annablume, 2015.

BENCOSTTA, Marcus Levy. Cultura cívico-escolar católica e desfiles patrióticos no Brasil do início do século XX. Varia História (UFMG. Impresso), v. 30, p. 391-403, 2014.

BORGES, Barsanufo Gomides. O despertar dos Dormentes: um estudo sobre a Estrada de Ferro Goiás e seu papel nas transformações das estruturas regionais. Goiânia: CEGRAF/UFG, 1990 (Coleção Documentos Goianos).

BRANDÃO, Hilma Aparecida. Memórias de um tempo perdido: a estrada de ferro Goiás e a cidade de Ipameri (início do século XX). 2005. 115 f. Dissertação (Mestrado em Ciências Humanas) - Universidade Federal de Uberlândia, Uberlândia, 2005. 
BRASIL. I Centenário das ferrovias brasileiras. Rio de Janeiro: IBGE, CNG, 1954.

BRASIL. Enciclopédia dos municípios brasileiros. XXXVI Vol. Rio de Janeiro: IBGE, 1958.

CASTILHO, Denis. Modernização Territorial e Redes Técnicas em Goiás. Goiânia: Editora UFG, 2016.

CASTILHO, Denis. Os sentidos da modernização. Boletim Goiano de Geografia, Goiânia, v. 30, n. 2, p. 125-140. 2010.

CASTRO, Maria Ines Malta. O preço do progresso: a construção da estrada de ferro Noroeste do Brasil (1905-1924). Dissertação (Mestrado). Unicamp, Campinas: 1993.

CHAUL, Nasr Nagib Fayad. Caminhos de Goiás: da construção da "decadência" aos limites da "modernidade". Goiânia: Ed. da UFG, Ed. da UCG, 1997.

COELHO, Gustavo Neiva. A ferrovia e o desenvolvimento do urbanismo e da arquitetura na região sudeste do estado. Revista UFG. Goiânia: Cegraf, 2011. Semestral.

COSTA, Beth et al. Ipameri, berço da modernidade em Goiás. Disponível em: http:// www.ypameri.com/old/html/fotos_historicas.html. Acesso em 13 de jul. 2017.

FERREIRA, Aroldo Márcio. A estação: portal do concreto e do imaginário. Revista UFG. Goiânia: Cegraf, 2011. Semestral.

GALVÃO, O. J. A. Desenvolvimento dos transportes e integração regional no Brasil: uma perspectiva histórica. Planejamento e Políticas Públicas, 13, jun., 1996.

GIESBRECHT, Ralph Mennucci. Estações ferroviárias do Brasil. Disponível em: $<$ www.estacoesferroviarias.com>. Acesso em 02 de julho de 2017.

HAESBAERT, Rogério. Da desterritorialização à multiterritorialidade. Anais do IX Encontro Nacional da ANPUR. Vol. 3. Rio de Janeiro: ANPUR, 2001.

INACIO, Paulo Cesar. Trabalho, Ferrovia e Memória: A experiência de turmeiro(a) no Trabalho Ferroviário. In: I Simpósio Internacional de História, 2003, Goiânia. 2003.

INSTITUTO MAURO BORGES - IMB. Regiões de Planejamento do Estado de Goiás. Goiânia: Seplan. 2006.

MARQUES, Edmilson Ferreira. A História do Rádio em Goiás (1942-1947). 2009. 247 f. Dissertação (Mestrado em Ciências Humanas) - Universidade Federal de Goiás, Goiânia, 2009.

NOGUEIRA, Wilson C. Pires do Rio: marco da história de Goiás. Goiânia: Roriz, 1977.

RAFFESTIN, Claude. Por uma Geografia do Poder. Tradução de Maria Cecília França. São Paulo (SP): Ática, 1993.

SANTOS, Milton. A Natureza do Espaço: Técnica e Tempo. Razão e Emoção. São Paulo: Hucitec, 1996.

SANTOS, Milton. Por uma outra globalização: do pensamento único à consciência universal. 10. ed. Rio de Janeiro: Record, 2003. 
SILVA, Sebastião da. Entrevista concedida à revista UFG, Dossiê Ferrovias. Revista UFG, Ano XII, No 11, Dezembro 2011. Disponível em: <https://www.proec.ufg.br/ up/694/o/11_entrevista_a_sebastiao.pdf $>$ Acesso em 2 de jul. 2017.

\section{Discografia}

ERBA, José Caetano. Mala Amarela. Intérpretes: Lourenço e Lourival. (s.d.).

Rômulo Hemilton Rocha Marinho

Bolsista Pibic, graduando em Geografia pelo Instituto de Estudos Socioambientais da Universidade Federal de Goiás e membro do Grupo de Estudos e Pesquisas sobre Redes e Produção do Território (GéTER). Campus Samambaia Caixa Postal 131. Goiânia - GO. CEP: 74001-970. E-mail: romulo135@gmail.com

\section{Dallys Dantas}

Professor da Secretaria Municipal da Educação de Aparecida de Goiânia. Graduado em Geografia pela Universidade Federal de Goiás, onde atualmente é mestrando pelo Programa de Pós-Graduação em Geografia. É membro do Grupo de Estudos e Pesquisas sobre Redes e Produção do Território (GéTER). Av. Hamburgo, Res. Metrópoles, Jd. Novo Mundo, Goiânia-GO, CEP: 74.703-110.

E-mail: dallysdantas@gmail.com

Recebido para publicação em abril de 2017 Aprovado para publicação em julho de 2017 